\title{
EL MARXISMO OCCIDENTAL O CRÍTICO BREVE RECUENTO DE SUS CARENCIAS
}

H. C. F. Mansilla*

El rápido colapso del socialismo en Europa Oriental a partir de 1989, la dramática descomposición de la Unión Soviética y la no tan sorpresiva declinación de instituciones y prácticas asociadas consuetudinariamente al marxismo han reavivado el debate en torno al fundamento teórico de un posible 'marxismo occidental o crítico'. ${ }^{1}$ El fracaso histórico del socialismo en general abre nuevamente el viejo debate sobre el valor analítico y prognóstico del marxismo, sobre la solidez de su base científica y las implicaciones éticas de esta doctrina. Aunque el marxismo exhibió desde un comienzo

* Universidad Mayor de San Andrés, La Paz, Bolivia.

${ }^{1}$ El término 'marxismo occidental' fue acuñado probablemente por Maurice Merleau-Ponty para denotar una corriente de pensamiento iniciada alrededor de 1923 por Georg Lukács y Karl Korsch y contrapuesta explícitamente a la ortodoxia moscovita. Cfr., Les aventures de la dialectique, 1955, París, Gallimard, p. 35 s.; Perry Anderson, Considerations on Western Marxism, 1976, Londres, New Left Books; Neil MacInnes, The Western Marxists, 1972, New York, Library Press; Ronald Aronson, After Marxism, 1995, New York, Guilford; Antonio Callari, et al. (comps.), Marxism in the Postmodern Age, 1995, New York, Guilford. 
una notable pluralidad programática e interpretativa y aunque el destino fáctico de los regímenes socialistas no conlleva imprescindiblemente una condena definitiva de la teoría que los inspiró, lo cierto es que ningún edificio conceptual queda incólume si la praxis le es adversa de manera persistente.

Los méritos del marxismo son substanciales y bien reconocidos; después de todo, el mundo contemporáneo ha sido moldeado parcialmente por las ideas y los ideales de sus partidarios. La contribución teórica del marxismo para comprender los fenómenos de enajenación y alienación -parte constitutiva de la modernidad- es indispensable y válida aún hoy. ${ }^{2}$ Como afirmó Friedrich Engels en 1883 (en su Oración fúnebre consagrada a su amigo Marx), la doctrina marxista brindó al proletariado la percepción ‘científica’ de su propia situación y la consciencia de las condiciones de su emancipación. Pero en un lapso de pocos años, el marxismo se transformó en un dogma impermeable al cambio y en un instrumento de dominación y disciplinamiento. Esta evolución, que comenzó en el seno de los partidos socialdemocráticos, fue consolidada y reforzada considerablemente por Vladimir I. Lenin y por la victoriosa Revolución de octubre en Rusia. ${ }^{3}$

${ }^{2}$ Pese a la crítica postmodernista, a lo recuperable corresponde también el aún fructífero análisis de Marx acerca de la diferencia entre valor de uso y valor de intercambio. Entre los muchos aspectos todavía válidos del opus marxista se encuentra, por ejemplo, la relevancia atribuida al vínculo entre pasión y verdad, esencial para el surgimiento y el avance del arte y la ciencia. Cfr. Karl Marx, Nationalökonomie und Philosophie (Economía política y filosofía = Manuscritos de París), en Marx, Die Frühschriften (Escritos tempranos), compilación de Siegfried Landshut, 1964, Stuttgart, Kröner, p. 275.

${ }^{3}$ A pesar de su importancia práctico-política, el marxismo en el Tercer mundo no ha producido innovaciones teóricas que hayan fructificado efectivamente el corpus de la doctrina a nivel mundial. La relevancia del marxismo tercermundista ha estribado en la creación de una ideología autoritaria de modernización acelerada, adornada con elementos socialistas y nacionalistas. 
Al lado de este 'marxismo institucional' (Leszek Kolakowski), protegido por las armas y el prestigio de una potencia mundial, han existido variantes de un 'marxismo crítico', opuesto a la ortodoxia moscovita, y del cual se esperaba hasta hace poco un pensamiento y una praxis genuinamente humanistas y emancipatorias y, simultáneamente, la readecuación de la doctrina original a la evolución del mundo contemporáneo. Este marxismo crítico no ha estado, empero, a la altura de los tiempos y de los conocimientos científicos generados fuera de él. Es importante comprender por qué estas tendencias críticas, que experimentaron a partir de 1968 un breve pero intenso renacimiento, se agotaron bien pronto, tanto en su función teórico-analítica como en su dimensión ético-política. Mucho antes de 1989 y del actual florecimiento de las escuelas postmodernistas y afines, el llamado marxismo crítico había cesado de jugar un rol importante en las ciencias sociales. Las contribuciones científicamente heurísticas y relevantes -como las de la Escuela de Frankfurt-se han dado prácticamente fuera de los presupuestos conceptuales y del horizonte de expectativas de todas las variantes del marxismo.

La obra pionera de Karl Korsch (1886-1961) se originó en la crítica del marxismo institucional en cuanto saber instrumental, es decir en el intento de retornar al marxismo primigenio como impulso esencialmente crítico, ético y emancipatorio. Su libro decisivo Marxismo y filosofía fue publicado en 1923, simultáneamente con la obra fundamental de Georg Lukács. Los dos puntos de partida de Karl Korsch son substanciales porque fundamentaron el desarrollo de un marxismo opuesto a la ortodoxia moscovita.

(A) Como todo fenómeno social y cultural, el marxismo está sujeto a sus propias premisas, a la historicidad y es, por ende, transitorio: no conforma una doctrina metafísica válida en todo tiempo y lugar (como lo suponía la vulgata socialdemocrática y la comunista), que sólo debe ser 'aplicada' adecuadamente para descifrar el universo material y social. Más que aseveraciones concretas sobre temas específicos, el marxismo estaría conformado por una actitud crítica ante los problemas de la esfera social-histórica y no frente a temas de las ciencias 
naturales. El corpus central del marxismo no es, según Korsch, positivo sino crítico, ${ }^{4}$ y la versión soviética del mismo se reduciría a ser una ideología justificatoria para implementar en la Rusia feudal un desarrollo capitalista. ${ }^{5}$ El despliegue de los hechos históricos y las 'necesidades' del movimiento comunista son factores que podrían explicar la involución del marxismo de una doctrina ético-revolucionaria a una teoría objetivista del desarrollo histórico obligatorio.

(B) La transformación del marxismo en un saber instrumental del poder fue posible porque Lenin y sus compañeros subordinaron el concepto de verdad bajo el criterio de eficacia político-partidaria, retornando además a doctrinas precríticas y pretranscendentales, es decir anteriores a Immanuel Kant en los campos de la gnoseología, la ética y ontología. ${ }^{6}$ Siguiendo las corrientes del positivismo burgués predominante, las leyes compulsivas del desarrollo histórico y la comprobación de hechos empírico-políticos fueron totalmente separadas de las cuestiones de moral y comportamiento práctico. ${ }^{7}$

El mérito de Korsch estriba en haber mostrado las consecuencias de una incipiente positivización del marxismo (que comenzó con Friedrich Engels), la que prescribe una dicotomía entre teoría y praxis, entre hechos y moral, dicotomía que fomenta el surgimiento de un saber legitimatorio del poder fáctico.

${ }^{4}$ Karl Korsch, Why I am a Marxist [1934], en Alternative. Zeitschrift für Literatur und Diskussion (Berlin), vol. 8, n 41, abril de 1965, p. 69, 71; Karl Korsch, Marxismus und Philosophie (Marxismo y filosofía) [1923], compilación de Erich Gerlach, 1966, Frankfurt, EVA, p. 34 s. (sobre la aplicación de la concepción materialista de la historia a esta misma).

${ }^{5}$ Karl Korsch, Zur Geschichte der marxistischen Ideologie in Russland (Sobre la historia de la ideología marxista en Rusia), en Der Gegner, vol. 1932, no 3, p. 9 s.

${ }^{6}$ Karl Korsch, Der gegenwärtige Stand des Problems 'Marxismus und Philosophie' (El estado actual del problema 'marxismo y filosofía') [1930], en Korsch, Marxismus, op. cit., (n. 4), p. 53 s.

${ }^{7}$ Korsch, Marxismus, op. cit., (n. 4), p. $101 \mathrm{s.}$ 
Georg [György] Lukács (1885-1971) ha sido ciertamente el pensador más importante de esta corriente y su libro Historia y consciencia de clase el fruto más sólido e importante de la misma, no superado hasta hoy. Uno de los méritos principales de Lukács reside en haber iniciado la discusión en torno a la temática enajenación / alienación, básica en Marx, pero prácticamente abandonada por la socialdemocracia -preocupada por cuestiones de estrategia política y la conquista del poder-y por el comunismo triunfante en la Unión Soviética, donde tal fenómeno propio del capitalismo simplemente no podía darse. Lukács realizó un espléndido análisis de esta problemática, mostrando la complejidad de la misma e introduciendo en la discusión el concepto hegeliano de cosificación. ${ }^{8}$

Inspirado por Max Weber, Lukács fue uno de los primeros marxistas en señalar los aspectos negativos que conllevan el progreso material y los procesos crecientes de racionalización, especialización, mecanización y despersonalización, responsables de la 'destrucción de la totalidad’ y la eliminación de la cultura genuina, por una parte, y productores de los fenómenos de cosificación, por otra. La atomización del individuo correspondería a la creciente irracionalidad de la totalidad social. ${ }^{9}$ Con este enfoque, que combina brillantemente las obras de

${ }^{8}$ Georg Lukács, Geschichte und Klassenbewusstsein. Studien über marxistische Dialektik (Historia y consciencia de clase. Estudios sobre dialéctica materialista), 1923, Berlín, Malik, p. 94-228.

${ }^{9}$ Lukács, ibid., p. 99 s., 115. Como se sabe, el libro de Lukács desató una impresionante ola de críticas y censuras de parte del marxismo oficial. Las más conocidas de ellas: Abram M. Deborin, Lukács und seine Kritik des Marxismus (Lukács y su crítica del marxismo) [1924], en Abram M. Deborin / Nikolaj I. Buxarin, Kontroversen über dialektischen und mechanistischen Materialismus (Controversias sobre el materialismo dialéctico y mecanicista), 1969, Frankfurt, Suhrkamp, p. 189-219; las diatribas de Grigorij Zinov'ev y otros altos funcionarios rusos y húngaros en el apéndice de: Georg Lukács, Schriften zur Ideologie und Politik (Escritos sobre ideología y política), 1967, Neuwied/Berlin, Luchterhand, compilación de Peter Ludz, p. 719-80. 
H. C. F. MANSILLA

juventud de Karl Marx con la sociología de Max Weber, Lukács inspiró la crítica de la técnica de Martin Heidegger y de la sociedad altamente industrializada realizada posteriormente por la Escuela de Frankfurt. La contribución del filósofo húngaro ha sido fundamental para todos aquellos pensadores que se consagraron al análisis de las consecuencias práctico-políticas del positivismo, empirismo y cientificismo. Pero lamentablemente Lukács no profundizó su enfoque: no diferenció, por ejemplo, entre una racionalidad instrumental -causante de la alienación- y una razón global objetiva. Él creyó que el proletariado revolucionario, como ‘idéntico sujeto-objeto’ de la historia, y la simultánea estatización de los medios de producción cortarían la cadena de racionalización y cosificación de las sociedades no emancipadas. No se imaginó, por otra parte, que la racionalidad instrumental sería la prevaleciente en regímenes socialistas, donde se darían fenómenos de enajenación muy similares a los del capitalismo occidental. ${ }^{10}$ Después de la censura proveniente de la ortodoxia moscovita inmediatamente después de la publicación de su libro, Lukács no perseveró en esta interesantísima temática.

Es necesario consignar, sin embargo, que Lukács, prosiguiendo una posibilidad contenida en la obra de Marx y también en la de Weber, dilató el alcance y la significación de cosificación, identificándola con objetivación y racionalización sin más, es decir, con todo el campo de lo social y el de la producción humana. Como señaló Emilio Lamo de Espinosa: “[...] entonces toda objetivación es alienación, y, por supuesto, superar la alienación, bien es un mito, bien exige al mismo tiempo superar toda objetividad. [...] Con ello la alienación devenía una condición humana, de hecho la condición humana”. ${ }^{11}$ Toda sociedad capitalista es percibida como una totalidad cerrada, inescapable, inamovible;

${ }^{10}$ Lukács, Geschichte, op. cit. (nota 8), p. 164 s., 216.

${ }^{11}$ Emilio Lamo de Espinosa, La teoría de la cosificación. De Marx a la Escuela de Francfort, 1981, Madrid, Alianza, p. 118; cfr. p. 120-3, 127 s., 152 s. (Se trata de una obra exhaustiva y con una excelente bibliografía sobre la temática.) 
sólo sería posible criticarla y superarla desde una posición exterior y transcendente al orden capitalista. Según Lukács, esto es dable desde la perspectiva del proletariado, pero esta suposición es frágil, ya que, por simple lógica, el proletariado no podría escapar a la acción niveladora del capitalismo tardío. Esperar la terminación de todo fenómeno de alienación por la revolución proletaria se asemeja mucho a esperar un milagro (como el mismo Lukács lo vio).

En el mismo libro (Historia y consciencia de clase) Lukács llevó a cabo otra hazaña teórica. Fue el primer marxista en criticar al padre fundador Friedrich Engels y la progresiva positivización del marxismo, tanto en su variante socialdemocrática como en la comunista, señalando que el ámbito de aplicación del método marxista es exclusivamente el terreno histórico-social y no el campo de la naturaleza. Con ello se opuso a una transformación del marxismo en una ciencia universal de pretensiones ontológicas y metahistóricas, como lo propuso Engels en sus escritos El Anti-Dühring y La dialéctica de la naturaleza. Lukács demostró que Engels confundió la praxis socio-política con las actividades de la industria, el laboratorio y el experimento, las que carecerían de la interrelación mutua entre sujeto y objeto y de la unidad entre teoría y praxis. De acuerdo a Lukács la identificación entre el mundo natural y el social, entre la praxis humana y la esfera de la fábrica y el laboratorio contribuye a producir un saber instrumental-dominacional apoyado sobre las leyes aparentemente irreversibles del desarrollo histórico, cuyo correlato sería la dialéctica en cuanto mera tecnología de la lucha política. El igualar sociedad y naturaleza (o praxis y trabajo alienado) conduciría al dilema irresoluble entre fatalismo y voluntarismo, entre libertad y necesidad. ${ }^{12}$

${ }^{12}$ Lukács, Geschichte..., op. cit., (n. 8), p. 33, 146-8. Sobre esta temática cfr. Hartmut Mehringer / Gottfried Mergner (comps.), Debatte um Engels (Debate en torno a Engels), 1973, 2 vols., Reinbek, Rowohlt; Alfred Schmidt, Der Begriff der Natur in der Lehre von Marx (El concepto de naturaleza en la doctrina de Marx), 1962, Frankfurt, EVA; Giuseppe Prestipino, El pensamiento filosófico de Engels. Naturaleza y sociedad en la perspectiva histórica marxista, 1977, México, Siglo XXI. 
H. C. F. MANSILLA

Lukács (y también Korsch) anticipó la crítica del positivismo realizada posteriormente por la Escuela de Frankfurt y otras corrientes humanistas al censurar la separación entre hechos y valores, entre teoría y praxis, entre política y ética que propugnaban destacados socialdemócratas y que luego pasó a ser la tendencia general de la ciencia social en Europa Oriental a partir de 1960. Este dualismo entre conocer y valorar reduce el rol de la razón al ámbito de la constatación empírico-experimental y elimina la jurisdicción de la misma en los campos de la praxis (política y ética), que dependen de juicios de valor y que bajo influencia positivista corren el peligro de caer en el decisionismo. ${ }^{13}$ Los 'técnicos del poder' se opusieron frontalmente contra esta concepción que privilegia impulsos emancipatorios y que roza el existencialismo.

Lukács complementó este teorema con una audaz redefinición del marxismo ortodoxo: este último es sólo el método (los modelos dialécticos para conocer y reconstruir la realidad) y no la teoría (los resultados e interpretaciones de la investigación científica). Aun en el caso de que se demostrara la inexactitud de cada uno de los enunciados de Marx, un 'marxista ortodoxo' podría desechar estas tesis de Marx, pero continuaría manteniendo la ortodoxia marxista si persiste en utilizar el materialismo dialéctico. ${ }^{14}$

Precisamente esta diferenciación entre teoremas y análisis concretos realizados por la doctrina marxista, por un lado, y el método históricodialéctico, por otro, ha posibilitado exégesis y teorías marxistas de carácter heurístico e innovativo en nuestro tiempo, ya que la preservación dogmática de todas las aserciones y los vaticinios de Marx y Engels habría conducido a una total esterilidad teórica. Pero esta separación tan severa entre método general y resultados específicos es altamente problemática: presupone la existencia de un núcleo irreductible del marxismo, un conjunto de fundamentos, métodos y principios que permanece incólume ante los avatares de los tiempos y también frente

${ }^{13}$ Lukács, op. cit., (n. 8), p. 33 s.

${ }^{14}$ Ibid., p. 13. 
MARXISMO OCCIDENTAL

a los progresos teóricos y gnoseológicos. Es improbable que existan estos cimientos genuinamente metafísicos, es decir fuera de toda contaminación física, histórica concreta, y menos aún que éstos sean compatibles con el enfoque eminentemente histórico de Marx. Es difícil imaginarse un edificio metodológico que permanezca válido si los diagnósticos y pronósticos fundamentados en el mismo son continuamente desautorizados por los sucesos históricos concretos y el avance científico.

El anatema que la ortodoxia moscovita lanzó ya en 1923 contra Historia y consciencia de clase llevó a Lukács a abandonar inmediatamente y para siempre sus enfoques más prometedores y heurísticos. La autocensura que se impuso el pensador húngaro estaba destinada a no malquistarse con el partido comunista. Es indispensable mencionar este tedioso asunto porque reflejó una actitud muy generalizada entre intelectuales: para estos seres solitarios y problemáticos el partido representó una especie de hogar, un lugar de redención que les brindaba la solidaridad que el mundo exterior, hostil y enajenado, no podía ofrecer.

Como se sabe, desde su ingreso al partido Lukács perteneció a la cúpula dirigente: fue Comisario del Pueblo para Educación y Cultura y Comisario Político de una división del Ejército Rojo (1919), y en estas actividades se destacó por su fanatismo y por la utilización de cualesquiera medios para consolidar el efímero poder bolchevique en Hungría. El fundamento de esta curiosa conversión y de su rudeza en el ejercicio del poder reside en un axioma al cual adhirió siempre y que trasluce una visión trágica de la vida: toda decisión es culpable. Sólo se podría elegir entre formas de aceptar la culpabilidad, y la única razonable sería "sacrificar el yo inferior en el altar de la idea superior”. ${ }^{15}$ El asesinato no está permitido, afirma Lukács, pero a veces hay que hacerlo -y entonces sería 'trágicamente moral’- para satisfacer la propia ética de dimensión histórica; el terrorista, por ejemplo, no

\footnotetext{
${ }^{15}$ Lukács, Taktik und Ethik (Táctica y ética) [1919], en Lukács, Schriften, op. cit., (n. 9), p. 10.
} 
H. C. F. MANSILLA

sólo sacrifica su vida por el prójimo, sino también su pureza, su moralidad, su alma. Los comunistas toman a su cargo los pecados del mundo para redimir el mundo pecaminoso. ${ }^{16}$ De lo malo puede entonces surgir lo bueno, y la mentira puede engendrar la verdad. Todo esto tiene el cinismo de la clásica justificación de los medios a causa de los fines, pero ahora la violencia es legitimada mediante argumentos mesiánicopolíticos: la monstruosidad del capitalismo exige para su eliminación el uso de métodos monstruosos. Poco después, en 1924, Lukács escribió que el Estado proletario constituiría el primer Estado en la historia que abiertamente admite ser un aparato de represión y un mero instrumento de la lucha de clases. ${ }^{17}$ Es superfluo decir que la ortodoxia soviética jamás aceptó la argumentación de Lukács: una cosa es practicar generosamente el terror revolucionario, y otra confesarlo públicamente y justificarlo por medio de teorías filosófico-teológicas. Por lo demás, este rigorismo intransigente es ciertamente trágico, pero en definitiva apolítico: Lukács -un místico existencialista- estaba más interesado por la redención inmediata del mundo profano por medios apocalípticos (la revolución proletaria total) que por la esfera de la actuación política, que es el campo de lo aleatorio, los arreglos y las negociaciones.

La doctrina de Lukács se basa en un axioma hegeliano: la libertad no es más que el reconocimiento de la necesidad. ${ }^{18} \mathrm{El}$ individuo actúa adecuadamente como ser social y 'supera' la necesidad si la reconoce y se somete a ella: el único modo realista de liberarse del sacrificio

${ }^{16}$ Ibid., p. 11. Sobre esta espinosa problemática cfr. Michel Löwy, Pour une sociologie des intellectuels révolutionnaires. L'évolution politique de Lukács 1909-1919, 1976, París, Presses Universitaires de France, passim, y la exhaustiva biografía de Arpad Kadárkay, Georg Lukács, 1994, Valencia, Edicions Alfons el Magnànim, passim.

${ }^{17}$ Lukács, Lenin. Studie über den Zusammenhang seiner Gedanken (Lenin. Estudio sobre el contexto de sus pensamientos) [1924], 1967, Neuwied/ Berlín, Luchterhand, p. 66.

${ }^{18}$ Lukács, Freie oder gelenkte Kunst? (¿Arte libre o guiado?), en Lukács, Schriften..., op. cit. (n. 9), p. 463. 
que es la historia consiste en soportar esas rigurosidades voluntaria y conscientemente. Y la necesidad histórica está personificada en el partido, que es, a su vez, la mediatización correcta entre teoría y praxis, la "manifestación organizativa de la voluntad revolucionaria del proletariado", ${ }^{19}$ la clase que lleva en su seno la racionalidad histórica superior y la emancipación del género humano. La mutua interacción entre partido y masas proletarias, entre voluntarismo y fatalismo, entre la regulación consciente de parte de la organización y la espontaneidad popular, produce, según Lukács, una mediatización infalible, una configuración visible y siempre correcta de la consciencia de clase proletaria anclada en el partido. La fuerza y la necesidad del partido se basan asimismo en que la consciencia de clase proletaria tiende a ser poco clara, lo que conlleva la justificación de una élite de revolucionarios profesionales. ${ }^{20}$ Lukács hizo explícita esta situación cuando censuró la famosa frase de Rosa Luxemburg: "La libertad es siempre la libertad del que piensa en modo diferente", corrigiéndola en este sentido: "La libertad ha de estar al servicio del poder proletario, pero éste no debe servir a aquélla." ${ }^{21}$ La democracia resulta ser una mera formalidad sin importancia substancial.

Lo fatal de Lukács y de muchos marxistas críticos es el nexo de esta concepción del partido con una filosofía de la historia que privilegia el éxito material como criterio de verdad superior. De acuerdo a ella en la realidad no hay lugar para lo contingente y casual: lo que sucede tenía que haber ocurrido así y no de otra manera. Aquí no hay campo para decisiones libres, nacidas de sopesar situaciones conflictivas y problemáticas, sino comportamientos ineludibles e inevitables. Este determinismo impide una ética de responsabilidad personal y un talante

${ }^{19}$ Lukács, Die moralische Sendung der kommunistischen Partei (La misión moral del partido comunista), en: Lukács, Schriften..., ibid., p. 138.

${ }^{20}$ Lukács, Taktik, op. cit. (n. 15), p. 34.

${ }^{21}$ Lukács, Geschichte, op. cit. (n. 8), p. 296. Parafraseando a Engels añadió Lukács: "Mientras el proletariado requiera de un Estado, no lo usará para defender la libertad, sino para reprimir a sus enemigos” (ibid., p. 297). 
H. C. F. MANSILLA

razonable ante los fenómenos políticos, que están signados por lo aleatorio. Si por ejemplo un proyecto, una política o una tendencia dentro del partido fracasan o quedan en la minoría, ello significa que la verdad y la razón históricas están en otra parte. La historia universal es el juicio final: ${ }^{22}$ los triunfadores materiales son los detentores de un derecho superior e ilimitado, y por ello pueden y deben obligar a la población a cualquier tipo de sacrificio.

Las consecuencias de todo esto son evidentes: pérdida de la dimensión crítica y deformación de los impulsos éticos, precisamente en lo que se refiere a la vida interna de los partidos. Se disipó así la posibilidad de una instancia imbuida de espíritu científico para esclarecer la estrategia y corregir los errores de la organización y, al mismo tiempo, se frustró un horizonte moral para iluminar la actuación individual. Lukács se contentó con un teorema mediocre y falso al afirmar que el peor de los socialismos es más aceptable que el mejor de los capitalismos. ${ }^{23}$ Lukács se asemeja, escribió Theodor W. Adorno, a un prisionero que arrastra sus cadenas y se imagina que este ruido es la marcha del espíritu del mundo, es decir del progreso histórico. ${ }^{24}$

A partir del Xx Congreso del Partido Comunista de la Unión Sovié90 tica (1956) surgieron vigorosas esperanzas en torno al renacimiento de un marxismo crítico y humanista, que estuviese además acorde con los avances de las ciencias sociales y naturales. Durante mucho tiempo la ortodoxia moscovita había condenado y prohibido como ‘burguesas' variadas ramas del saber como la psicología, la cibernética, la sociología

${ }^{22}$ Lukács, Schicksalswende (Vuelta del destino) [1944], en: Schriften..., op. cit. (n. 9), p. 354.

${ }^{23}$ Testimonios suplementarios de esta afirmación en: István Eörsi, Das Recht des letzten Wortes (El derecho de la última palabra), en Georg Lukács, Gelebtes Denken. Eine Autobiographie im Dialog (Pensamiento vivido. Una autobiografía en diálogo), 1980, Frankfurt, Suhrkamp, p. 10 s.

${ }^{24}$ Theodor W. Adorno, Erpresste Versöhnung: zu Georg Lukács' “Wider den missverstandenen Realismus" (Reconciliación extorsionada: sobre la obra de Lukács 'Contra el realismo incomprendido'), en Adorno, Noten zur Literatur II (Notas sobre literatura II), 1961, Frankfurt, Suhrkamp, p. 185. 
MARXISMO OCCIDENTAL

y la antropología. ${ }^{25}$ Pero desde 1960 estas disciplinas experimentaron un notable florecimiento que habría repugnado a los fundadores del marxismo occidental, Georg Lukács y Karl Korsch: purificadas metódicamente de todo elemento crítico y cuestionador del status quo se transformaron en dóciles instrumentos del poder establecido.

La formalización y positivización de las ciencias sociales en Europa oriental, hecho que en Occidente fue calificado como una saludable desideologización de esas disciplinas, impidió que brote un marxismo genuinamente crítico; la sociología, por ejemplo, se convirtió en un saber apolítico, consagrado a compilar y sistematizar datos sobre la población, su estructura y sus hábitos, que las autoridades utilizaron para controlar, guiar y aprovechar mejor los llamados 'recursos humanos' ${ }^{26}$ La inmensa masa de estos estudios rendía un homenaje verbal al marxismo y a sus padres fundadores, para luego pasar rápidamente a los aspectos técnicos, entre los cuales sobresalía la preocupación por hallar leyes inexorables en todos los terrenos y por acomodarse al orden establecido, estimado como insuperable. La República Democrática Alemana se distinguió, por ejemplo, por la creación de la deóntica, una ética altamente formalizada y matematizada, totalmente exenta de juicios valorativos y críticos, dedicada a medir y mejorar el comportamiento humano en el lugar de estudio y trabajo, cuya presuposición básica era la concepción de la sociedad como un perfecto sistema cibernético de autorregulación permanente. ${ }^{27}$

${ }^{25}$ Gabor Kiss, Marxismus als Soziologie (Marxismo como sociología), 1971, Reinbek, Rowohlt, p. 107.

${ }^{26}$ No fue la sociología teórica la que floreció, sino sus ramas ‘aprovechables' según los requerimientos del Estado: las sociologías del trabajo, la familia, el esparcimiento y la educación (cfr. Gabor Kiss, ibid., p. 157-93, 267-93); en los estudios sobre estratificación social se eliminó toda mención a la formación de élites y a conceptos definitorios de estamentos de índole incómoda como el prestigio y el acceso al poder (ibid., p. 88-106, 174-201).

${ }^{27}$ Wolfgang Eichhorn, Wie ist Ethik als Wissenschaft möglich? (¿Cómo es posible la ética en cuanto ciencia?), 1965, Berlin/RDA, Verlag der Wissenschaften; Franz Loeser, Deontik. Planung und Leitung der moralischen 
H. C. F. MANSILLA

Estas inclinaciones apolíticas y acríticas, que harían las delicias de cualquier tecnócrata, no fueron ajenas a los intentos reformistas más atrevidos, como la 'Primavera de Praga' de 1968. Aparte de los pocos literatos y filósofos que tuvieron entonces un papel destacado en el manejo de la cosa pública, aquel breve gobierno checoslovaco estuvo fuertemente influido por un grupo de funcionarios y ministros que poco antes había formulado el llamado Informe Richta. Un somero vistazo a las publicaciones pertinentes es revelador porque muestra el carácter tecnocrático de las preocupaciones de los reformistas checoslovacos y el aporte casi nulo a la conformación de un marxismo crítico. El futuro, principal tema de inquietud, es concebido exclusivamente de acuerdo a criterios técnico-económicos; la idea de un 'socialismo democrático’, que hizo famoso a este grupo, se reduce a una modernización acelerada de todos los sectores económicos relevantes y a la preservación (a) del monopolio del poder en manos de los comunistas y (b) de la propiedad estatal sobre los principales medios de producción. El modelo es, en el fondo, una economía socialista planificada, enriquecida con ciertos elementos de mercado y la vigencia de los derechos humanos. ${ }^{28}$ No hay lugar alguno para un pluralismo ideológico o de partidos, aunque se asevera que el partido debe cumplir una 'misión humana'; precisamente en medio de la discusión sobre los derechos humanos se reafirma taxativamente que el principio de rendimiento debe configurar el criterio central de la vida ecnómica y social. ${ }^{29}$ Sería inútil buscar una sola mención a la temática de la enajenación en sociedades altamente industrializadas o una palabra crítica acerca de asuntos ecológicos o de los efectos negativos del progreso material.

Entwicklung (Deóntica. Planificación y dirección del desarrollo moral), 1966, Berlín/ RDA, Verlag der Wissenschaften.

${ }^{28}$ Radovan Richta et al., Technischer Fortschritt und industrielle Gesellschaft (Progreso técnico y sociedad industrial), 1972, Frankfurt, Makol, p. 12 s., 21-4, 191-230.

${ }^{29}$ Ibid., p. 23 s., 208, 214-6, 226. 
MARXISMO OCCIDENTAL

Extrapolando la doctrina de los reformistas checoslovacos a otros grupos de marxistas heterodoxos en Europa oriental y el Tercer mundo, se puede concluir que su preocupación básica giró alrededor de una modernización acelerada, que hubiera garantizado la llamada legalidad socialista, pero que ante todo sirviera para alcanzar el nivel de producción y consumo de Europa occidental, el cual, mutatis mutandis, conservaba su función de meta normativa digna de ser imitada y alcanzada a la brevedad posible. De ahí la indulgencia con que se juzgó todo proceso de industrialización forzada -incluyendo específicamente el modelo stalinista- ya que, como afirmó Lucio Colletti, la creación de la gran industria en Rusia habría poseído un inmenso 'efecto liberador': los campesinos transformados en obreros de fábricas, los nómadas del Asia Central asentados en grandes aglomeraciones urbanas, la artesanía convertida en industria automatizada. ${ }^{30}$ Esta concepción incluye el tradicional desprecio por todas las tradiciones pre-industriales y por la esfera agraria (Marx: 'la estupidez de la vida campesina') y la admiración concomitante por la modernidad citadina, por más mediocre que ésta resulte ser. Esta gran visión tecnocrática ha dejado de lado definitivamente los grandes temas del marxismo crítico -el saber apolítico como instrumento del poder, el incremento de los fenómenos de alienación en la época contemporánea, la unidad de teoría y praxis- y se ha concentrado en tareas subalternas pero imprescindibles en la actualidad: investigación empírica en temas dictados por necesidades burocrático-administrativas, alta formalización del conocimiento y elaboración de técnicas eficientes en áreas bien delimitadas para consolidar los saberes dominacionales.

Los aportes de tenor más filosófico y político tampoco significaron una renovación genuinamente teórica del marxismo institucional y menos una contribución innovadora a los temas específicos que Korsch

${ }^{30}$ Lucio Colleti, Zur Stalin-Frage (Sobre la cuestión de Stalin) [1970], 1970, Berlin/W, Merve, p. 34-7. En esta obra Colletti describe detalladamente las brutalidades del régimen stalinista, pero lo exculpa históricamente a causa de los logros modernizadores. 
y Lukács señalaron en 1923. La brillante obra de Ernst Bloch (18851977) recupera la herencia teológica y mística del marxismo y se encuentra, por ende, alejada de toda inclinación positivista y tecnocrática, pero en ningún momento pone en duda las simplificaciones leninistas, las prácticas stalinistas ni el desprecio de la ortodoxia moscovita por la 'democracia formal'. ${ }^{31}$ En un plano muy diferente se halla la labor de Palmiro Togliatti (1893-1964), quien hacia el final de su vida propugnó un comunismo ‘civilizado’, pragmático, exento de maximalismos y respetuoso de las peculiaridades nacionales; pero asimismo este esfuerzo no engendró ningún impulso teórico digno de mención (y menos aún donde se lo hubiera podido esperar, como ser una crítica de la mentalidad imperante en el interior del partido y de la tradicional cultura política del autoritarismo). ${ }^{32}$

El análisis del llamado 'marxismo existencialista' de Europa oriental depara la misma decepción: con la pretensión de llevar a cabo una investigación realmente original e incorporar temas descuidados por el marxismo convencional, esta corriente de pensamiento reiteró ideas y postulados totalmente convencionales bajo un ropaje que sólo en el ámbito gris del neostalinismo podía aparecer como una novedad. El filósofo checoslovaco Karel Kosík, por ejemplo, se propuso reconstruir la relación entre el individuo y el mundo moderno bajo la perspectiva de la 'dialéctica' de ser y aspecto, esencia y existencia, consciencia e ideología, pero su farragoso texto jamás deja las etéreas esferas de la teoría más abstrusa y nunca desciende a los problemas específicos

${ }^{31}$ Para la problemática aquí tratada es importante la compilación de ensayos de Ernst Bloch, Über Karl Marx (Sobre Karl Marx), Frankfurt: Suhrkamp 1968; en torno a Bloch cfr. el volumen colectivo Über Ernst Bloch (Sobre Ernst Bloch), 1968, Frankfurt, Suhrkamp, especialmente el artículo de Iring Fetscher, Ein grosser Einzelgänger (Un gran solitario), en ibid., p. 104-11 (con datos en torno a la influencia de Bloch sobre Georg Lukács y la Escuela de Frankfurt).

${ }^{32}$ Palmiro Togliatti, Reden und Schriften (Discursos y escritos), compilación de Claudio Pozzoli, 1967, Frankfurt, Fischer; cfr. sobre todo su testamento intelectual, llamado ‘Memorandum de Yalta’: p. 210-25. 
que atormentaban a las personas concretas en Europa oriental. No hay duda de que esta temática fue mejor tratada por los poetas y los novelistas que por los pensadores desde cátedras bien pagadas.

Las conclusiones de Kosík son notables: el Hombre “fundamenta y justifica su actividad cuando se percibe a sí mismo como instrumento de un poder suprapersonal", es decir cuando creyendo realizar sus intenciones, en el fondo ejecuta las leyes de hierro de la historia. ${ }^{33} \mathrm{Si}$ alguien comete un asesinato por razones personales, lleva a cabo evidentemente un vulgar delito. Pero si el mismo acto es perpetrado en el marco de una ‘intención superior’ y como instrumento de la ‘necesidad histórica’, entonces se convierte en "venganza, justicia, juicio histórico, obligación civil, hecho heroico”. ${ }^{34}$ A esto no hay mucho que agregar.

También el filósofo y político polaco Adam Schaff se ha preocupado por lo problemático de la existencia humana y la soledad del individuo en la civilización industrial, constatando que esta temática ha sido descuidada por el marxismo institucional a causa de la dedicación de este último a cuestiones que en cierto momento eran más urgentes: la acción revolucionaria de las masas proletarias, la organización del régimen socialista, la necesidad de mejorar las estructuras económicas. Pero en contra del existencialismo francés, Schaff sostuvo que el objeto adecuado de estudio no lo constituía el individuo autónomo y aislado del mundo burgués, sino la persona responsable inmersa en la esfera de la praxis en una sociedad determinada por leyes evolutivas. ${ }^{35}$ En el seno del marxismo institucional Schaff fue el primero en admitir que los

\footnotetext{
${ }^{33}$ Karel Kosík, Die Dialektik des Konkreten. Eine Studie zur Problematik des Menschen und der Welt (La dialéctica de lo concreto. Un estudio sobre la problemática del Hombre y del mundo), 1967, Frankfurt, Fischer, p. 230.

${ }^{34}$ Ibid., p. 231. Hay que considerar que este libro fue escrito poco antes de la 'Primavera de Praga' y sin las presiones del régimen stalinista.

${ }^{35}$ Cfr. Adam Schaff, Marx oder Sartre? Versuch einer Philosophie des Menschen (¿Marx o Sartre? Ensayo de una filosofía del Hombre), [1961], 1966, Frankfurt, Fischer, p. 15, 23; Schaff, El marxismo al final del siglo, 1994, Barcelona, Ariel.
} 
H. C. F. MANSILLA

fenómenos de alienación existían también en el orbe socialista debido al mantenimiento del aparato estatal; lo que Schaff no aceptó fue la mera idea de una enajenación causada igualmente por la configuración de la economía socialista, pues según él la estatización de los medios de producción en Polonia había terminado definitivamente con la causa substancial de la alienación en la esfera laboral-económica. ${ }^{36}$

Pese a un comienzo brillante y promisorio con Karl Korsch y Georg Lukács, el llamado marxismo crítico no logró, en el fondo, superar las insuficiencias y los aspectos dogmáticos de la ortodoxia moscovita, la que, protegida por las armas de una potencia mundial, tenía a su favor ciertos factores nada despreciables: el prestigio de encarnar la herencia legítima de los padres fundadores, la hazaña de haber realizado la primera revolución socialista de la historia universal y el éxito material. Los pensadores adscritos a la corriente crítica exhibieron una especie de consciencia de culpabilidad frente a la ortodoxia soviética y preservaron una imagen embellecida del modelo iniciado en 1917, cuya función mistificadora les era bien conocida. Con la posible excepción de Korsch ninguno de ellos se atrevió, por ejemplo, a reconocer que la Revolución de octubre había surgido de un golpe de Estado militar bastante convencional y que ni el proletariado ruso ni las condiciones socio-culturales y económicas de aquel país estaban maduras para un régimen socialista según la concepción original de Marx. Ninguno de ellos se atrevió asimismo a examinar la hipótesis de que el marxismo (y especialmente su versión leninista) no representaba, en el fondo, la doctrina del proletariado revolucionario, sino la ideología de los intelectuales que anhelaban imponer su propio dominio de clase, su conquista del poder para y por ellos, encubriendo este designio mediante una doctrina de la emancipación general del género humano. ${ }^{37}$

${ }^{36}$ Adam Schaff, Marxismus und das menschliche Individuum (El marxismo y el individuo humano), 1965, Viena, p. 38 s., 170.

37 György Konrád / Iván Szelényi, Die Intelligenz auf dem Weg zur Klassenmacht (La intelectualidad en camino al poder de clase), 1981, Frankfurt, Suhrkamp, p. 111 s. 
Casi todos los marxistas críticos han adherido al axioma de que un mal socialismo es preferible a un buen capitalismo. Esto se debe, entre otras causas, a una notable incomprensión de la esfera político-institucional, que proviene del núcleo del marxismo primigenio. La creencia en las leyes inexorables de la historia, la mística revolucionaria de una misión superior y el odio al enemigo de clase han imposibilitado (1) el surgimiento de una genuina ética de responsabilidad individual y grupal, que se rija también por el principio de la proporcionalidad de los medios), (2) una apreciación cabal de los elementos mal llamados formales de la moderna democracia representativa y pluralista, (3) un reconocimiento de la legitimidad de los intereses inherentes a corrientes y partidos que no son los propios, y (4) la admisión de que la liberación del individuo no ocurre necesariamente por medio de la emancipación de la especie.

Desde el marxismo original se arrastran algunas insuficiencias para comprender el mundo contemporáneo, que no han sido subsanadas por los marxistas críticos. En el trabajo teórico la fuerte tendencia economicista y tecnicista ha conducido a una subvaloración casi permanente de las tradiciones culturales en cuanto factores históricos de primer rango; salvo Karl Korsch -y su aporte fue muy tangencial- no se puede detectar una línea investigativa que hubiera tomado en serio el legado autoritario de Rusia, Europa oriental y buena parte del Tercer mundo como agente formativo en el seno de los partidos comunistas y de las nuevas burocracias establecidas con las revoluciones socialistas. El persistente desprecio de todo modelo democrático y la exaltación de la dictadura del proletariado como forma superior de organización social han minado las bases internas del movimiento obrero y de los grupos intelectuales, desde las cuales se hubiese podido mitigar las inclinaciones despóticas y las prácticas burocráticas que resultaron tan expandidas dentro de los partidos comunistas. La excesiva confianza en las leyes inexorables de la historia y la propensión a percibir en los grandes proyectos técnicos la solución de todos los problemas sociales -es decir: la unión de dogmatismo convencional con ilusiones tecnicistas-impidieron advertir la relevancia de algunos de los fenómenos 
más importantes de la segunda mitad del siglo Xx, como el nacionalismo y la religión, que fueron ignorados por casi todos los marxistas críticos. El sesgo tecnicista de todas las versiones del marxismo conlleva una sintomática equiparación entre la emancipación del género humano y el despliegue de las posibilidades de la tecnología, una confusión optimista propia de casi todos los pensadores del siglo XIX.

También el marxismo primigenio denotaba un fuerte eurocentris$m o:{ }^{38}$ en conjunción con los elementos anteriores, éste ha sido responsable por el abierto menosprecio dirigido hacia lo pre-industrial, lo pre-moderno, lo extra-europeo, y concomitantemente, hacia lo diverso y variopinto, que es lo que se resiste a la homogeneización industrialmoderna. Naciones pequeñas que no se dejan tragar por las grandes, grupos étnicos que se aferran a sus peculiaridades, instituciones curiosas que han crecido orgánicamente a lo largo de siglos, estructuras y estamentos sociales que no encajan en el esquema marxista, y actividades culturales sin correspondencia explícita con los 'fenómenos de clase’ han sido desdeñadas u olvidadas por el marxismo crítico.

Una de las principales insuficiencias del marxismo crítico es su capacidad relativamente limitada de comprender la complejidad del mundo moderno de manera realista. Su posición simplista y por momentos moralista le impidió percibir las múltiples funciones que cumplen los medios generales y generalizables de la modernidad: el dinero y el poder. La identificación de éstos con las fuentes centrales de la alienación deja de lado los variados, razonables e imprescindibles roles que estos medios cumplen para hacer caminar las complicadas sociedades actuales. De ahí la ilusión de que la eliminación de la propiedad privada sobre los medios de producción terminaría pronta y definitivamente con la fuente principal de la enajenación, lo que resultó falso.

${ }^{38}$ Sobre el etnocentrismo, sus claras manifestaciones en Marx y la defensa que hizo éste último de la ‘labor civilizadora’ del imperialismo británico en India y otros países 'atrasados’ cfr. Rudolf Bahro, Die Alternative. Zur Kritik des real existierenden Sozialismus (La alternativa. Crítica del socialismo realmente existente), 1980, Reinbek, Rowohlt, p. 44 s. 
En la misma línea Marx y sus discípulos críticos sobrevaloraron las tareas que el Estado debía cumplir en la etapa socialista, una vez superado el modo capitalista de producción; no se imaginaron, sobre todo, que el aparato estatal podría reproducir y hasta magnificar el legado autoritario de muchas tradiciones culturales, creando una administración pública hipertrofiada y burocratizada, junto con una élite política munida de las prerrogativas más odiosas. Marx y los marxistas críticos no concibieron la posibilidad de un estrato altamente privilegiado a causa de su acceso al poder y de su control sobre la enorme burocracia (sin poseer los medios de producción en sentido legal), y, por lo tanto, no se preocuparon de medidas e instituciones que regulen y refrenen sus dilatadas potestades. Marx, Lenin y hasta los marxistas críticos creyeron que el socialismo y la estatización de los medios de producción traerían consigo 'la administración de cosas' en lugar del 'gobierno de las personas' (Engels), pero no advirtieron que las cosas se administran siempre junto a hombres de carne y hueso y que cualquier administración (y con más razón una inmersa en un mundo complejo) significa el establecimiento de competencias, la creación de jerarquías, la especialización de roles y el surgimiento de privilegios. Esta necesaria diferenciación de grupos y estratos no concuerda con el esquema estático y relativamente simple que Marx propuso y que sus discípulos conservaron en lo fundamental: en los países altamente desarrollados no llegó a constituirse un proletariado revolucionario, consciente de su situación de clase inmensamente mayoritaria y de su misión histórica y revolucionaria, que tomara a su cargo la emancipación de la sociedad como totalidad. La consciencia de clase de los obreros en el capitalismo occidental resultó ser afín al reformismo socialdemocrático, puesto que sus ilusiones y esperanzas cotidianas no tenían como punto de referencia las nostalgias utópicas y milenaristas de los intelectuales marxistas. La postulada redención del mundo histórico-político se quedó así sin una clase socialmente mayoritaria que le sirva de sustrato material.

Finalmente el marxismo crítico no anticipó ni realizó aportes significativos a los debates de las últimas décadas. La discusión ecológica y demográfica, la investigación de la cultura de masas, las aporías de 
H. C. F. MANSILLA

la civilización industrial, las diferencias entre trabajo, praxis e interacción, las contribuciones del psicoanálisis socio-político y los aspectos negativos asociados (1) a toda modernidad, (2) al igualitarismo excesivo y (3) al progreso material incesante, quedaron fuera del horizonte teórico del marxismo crítico, que por ello no ha logrado aprehender la complejidad del mundo contemporáneo. 